\title{
An Empirical Research of Supervisor-subordinate Guanxi
}

\author{
Tung-Ju Wu \\ Business School of Huaqiao University. \\ Quanzhou 362021, China.
}

\begin{abstract}
The factors in turnover might be an organization not being able to provide satisfactory working environment for employees and the work identity of employees. Supervisorsubordinate guanxi is especially emphasized in Chinese enterprises, and such guanxi culture is the maxim in Chinese societies. The results the moderation of supervisor-subordinate guanxi, ones with better supervisor-subordinate guanxi present lower turnover intention than those with worse supervisorsubordinate guanxi.
\end{abstract}

Keywords-turnover intension, organizational commitment, job security, supervisor-subordinate guanxi

\section{INTRODUCTION}

The continuous financial crises and export crunch in past years have largely impacted the employment market in Taiwan. According to the statistics, the unemployment in Taiwan remains high and is even increasing. Under the news of high unemployment rate, corporate bankruptcy and layoff, the spread of job insecurity has resulted in great influence and insecurity on organizations and employees. Employees bear even more stress and are suffering from the anxiety of unemployment. In current working environments, employees reveal increasing desire for job security and worry about the continuity of job that the work attitudes and career planning are affected.

High turnover rate has been a problem of human resource management for enterprises. In spite of the necessity of turnover rate for the growth of an enterprise, improper or frequent turnover rate would influence the quality of customer services and result in the gap in experience inheritance of organizational members. Employees consider organizational commitment, leadership styles of supervisors, and organizational culture in an enterprise as the factors in the job satisfaction[1][2][3]. Past research pointed out the higher organizational commitment of employees, the lower turnover intention, the better work attitudes, and the higher job satisfaction. For this reason, when the factors in job satisfaction of organizational members are properly controlled, remedial measures could be adopted to enhance employees' job satisfaction and effectively promote the morale and reduce the turnover rate. It shows positive effects on an organization[4][5].

Chinese societies and organizations particularly stress on the bonding of individual guanxi[6] and the normative

\author{
Ting Xu \\ School of Management. Shanghai University. \\ Shanghai 200444, China.
}

obligations of reciprocity and exchange. Guanxi is also directional and can be divided into vertical supervisorsubordinate guanxi and horizontal colleague guanxi among different departments in order to expand the power and influence[6]. Guanxi, being a special resource in an enterprise, could protect the status of the owner in the enterprise as well as consolidate the power of "one of us"[6]. Furthermore, the cultural background in Chinese societies presents distinctiveness, and the etiquette, commitment, and prestige among people are particularly emphasized[7]. In an enterprise, the abusive supervision of a supervisor would affect employees' altruism and organizational commitment in the enterprise and could easily result in supervisor-subordinate guanxi conflict[8], especially when subordinates perceive unfair treatment from supervisors[9].

\section{LITERATURE REVIEW}

2.1 Job Security, Organizational Commitment and Turnover Intension

According to Hierarchy of Needs and Two Factor Theory, personal security factors were the fundamental needs. The so-called personal needs of safety refer to not being invaded or threatened physically and mentally and not surviving in panic life. Maslow[10] also mentioned that, in addition to physical security, employees would expect to acquire needs of job security, covering job stability and seniority security. Job security from an enterprise, including employees' physical and mental health, job satisfaction, organizational commitment, and the reduction of turnover intention, would affect the employees' work attitudes and work results. On the contrary, an employee would be hurt the physical and mental health when perceiving job insecurity to result in negative effects on the job satisfaction[11][12], reduce the organizational commitment[13], and increase the turnover intention[14][15]. In sum, job security offered by an enterprise would indeed affect personal work attitudes and behaviors of an employee. An employee when perceiving job insecurity would easily generate negative effects and even appear turnover behaviors. It is therefore considered in this study that Hypothesis 1: employees perceiving high job security would reduce the turnover intention.

By reviewing the past research on organizational commitment, Allen and Meyer[16] classified organizational commitment into affective commitment, continuance commitment, and normative commitment. Organizational 
commitment could be regarded as employees' intention to stay in the enterprises as well as a kind of work attitudes towards organizational loyalty[17][18]. It could be a kind of employees' organizational attachment where compliance, identification, and internalization were utilized for defining organizational commitment[19]. When employees reduce the loyalty or appear mistrust and disidentification, the organizational commitment is reduced that they are likely to present dissatisfaction and increase the turnover intention. As a result, it is regarded in this study that Hypothesis 2: employees with higher organizational commitment would reduce the turnover intention.

\subsection{Supervisor-subordinate Guanxi}

Guanxi is a historical and specific culture in Chinese societies. The special interpersonal relationship in Chinese societies became the focus since Fei[20] proposed the idea of Chaxugeju. The idea of guanxi in Chinese societies was originated from Confucianism[21] and offered the role positioning of an individual in the society and the behavioral rules for getting along with others to become the key value in the interpersonal relationship in Chinese societies. Yang[22] argued that guanxi was the correlation among objects, forces, and persons; especially, it could be a kind of "social connection" when the correlations among people were emphasized; such guanxi was established on shared benefits and profits[6]. Guanxi is a specific transactional relationship between partners in which they acquire benefits by exchanging preference. Renqing and mianzi are the favorable media.

Referring to Chaxugeju proposed by Fei[20], Hwang[21] divided guanxi into expressive, mixed, and instrumental guanxi and indicated that different types of guanxi would result in distinct interaction rules. For instance, individualfamily guanxi was a permanent and stable social guanxi, as expressive guanxi; salesperson-customer/stranger guanxi was to acquire personal material goal through benefit exchange, as instrumental guanxi; and teacher-student, colleague, and classmate guanxi presenting certain affection after contact, but not as close as family members, was mixed guanxi. Based on above guanxi standards, supervisor-subordinate guanxi should be a kind of mixed guanxi, i.e. covering both expressive and instrumental contents. Tsai et al.[6] revealed that managers with friend guanxi played the role of a communication bridge between chief managers and subordinates as well as the function of lubricant in an enterprise.

Taormina and Gao[24] mentioned that different guanxi behaviors would show distinct influence, such as job satisfaction, mutual support among employees in an organization, and self-attribution to success. The better supervisor-subordinate guanxi in an enterprise, the better mistakes being forgiven and forgot, the better subordinates' affective commitment being enhanced, the higher employees' organizational commitment, and the higher supervisors' leadership effectiveness[6][23]. It is therefore considered that the better supervisor-subordinate guanxi could release employees' perceived inadequate job security and low organizational commitment to reduce the turnover intention. Hypothesis 3: supervisor-subordinate guanxi presents moderation between perceived job security and turnover intention of employees. Hypothesis 4: supervisor-subordinate guanxi appears moderation on organizational commitment and turnover intention of employees.

\section{METHODS}

Middle management of enterprises in Taiwan is researched in this study. The research data are collected with questionnaire survey. With the assistance of local associations, enterprises are first confirmed the intention of being interviewed through telephones or emails and further made appointment for the questionnaire survey. Total 142 enterprises are surveyed with 1-3 copies of questionnaire, and total 383 valid copies are retrieved. In the samples, 67 percent is males and their supervisors are almost male. The mean age is 35.3 years and seniority is 8.7 years. About the type of guanxi, total 47 percent of the samples reveal family guanxi with their executives, friend guanxi about 31 percent and favor-exchange Guanxi 22 percent. A total of 67 percent of the samples is manufacturing and almost 71 percent of their job function is operating.

Perceived job security is Based on the job security scale proposed by Caplan, Cobb, French, Van Harrison and Pinneau[25], this part contains three questions and is measured with Likert 5-point scale. The Cronbach's $\alpha$ appears 0.85 . Organizational commitment is Based on the organizational commitment scale proposed by Allen and Meyer[16], total 18 questions are covered and measured with Likert 5-point scale. The Cronbach's $\alpha$ appears 0.88. Turnover intention is measured with Likert 5-point scale. The Cronbach's $\alpha$ reveals 0.85 . Supervisor-subordinate guanxi is measured with Likert 5-point scale. The Cronbach's $\alpha$ is 0.96 .

\section{CONCLUSION}

Under the moderation of supervisor-subordinate guanxi, it is also found that ones with better supervisor-subordinate guanxi would show better perceived job security and organizational commitment to reduce turnover intention. Supervisor-subordinate guanxi is a new concept proposed in recent years, which emphasizes the elements of affection, reciprocity, and trust. Meanwhile, supervisor-subordinate guanxi is a product of Chinese culture. The concept stresses that the trust and affection between supervisors and subordinates are not merely generated in business, but are the key to establish trust and affection in private. Guanxi focuses on the contact among people in informal situations and is an important principle of interaction in Chinese societies. Supervisor-subordinate guanxi is a kind of mixed guanxi which contains both expressive and instrumental contents. Such expressive guanxi would guide both parties to a different 
boundary and generate "fetters". Higher than tasks and hierarchical systems, such fetters are established based on affection. For this reason, when the establishment of supervisor-subordinate guanxi exceeds the job specifications, it would assist subordinates in reducing the turnover intention.

\section{References}

[1] Harris, T.B., Li, N., \& Kirkman, B.L., Leader-member exchange (LMX) in context: How LMX differentiation and LMX relational separation attenuate LMX's influence on OCB and turnover intention, The Leadership Quarterly, 25(2), 2014, 314-328.

[2] Mathieu, C., Neumann, C.S., Hare, R.D., \& Babiak P., A dark side of leadership: corporate psychopathy and its influence on employee wellbeing and job satisfaction, Personality and Individual Differences, 59, 2014, 83-88.

[3] Winkler, E., Busch, C., Clasen, J., \& Vowinkel, J., Changes in leadership behaviors predict changes in job satisfaction and well-being in low-skilled workers: A longitudinal investigation, Journal of Leadership \& Organizational Studies, 22(1) , 2015, 72-87.

[4] Valentine, S., Godkin, L., Fleischman, G.M., \& Kidwell R., Corporate ethical values, group creativity, job satisfaction and turnover intention: The impact of work context on work response, Journal of Business Ethics, 98(3), 2011, 353-372.

[5] Demirtas, O., \& Akdogan, A.A., The effect of ethical leadership behavior on ethical climate, turnover intention, and affective commitment, Journal of Business Ethics, 130(1), 2015, 1-9.

[6] Tsai, H.T., Wu, T.J., \& Yeh S.P., A study of Chinese guanxi type in family business from the perspective of power-based and leadership behaviours, South African Journal of Economic and Management Sciences, 16(5), 2013, 102-114.

[7] Liu, J., Kwong Kwan, H., Wu, L.Z., \& Wu W., Abusive supervision and subordinate supervisor - directed deviance: The moderating role of traditional values and the mediating role of revenge cognitions. Journal of Occupational and Organizational Psychology, 83(4), 2010, 835-856.

[8] Liu, X.Y., \& Wang, J., Abusive supervision and organizational citizenship behaviour: is supervisor-subordinate guanxi a mediator? The International Journal of Human Resource Management, 24(7), 2013, 1471-1489.

[9] Hom, P.W., Mitchell, T.R., Lee, T.W., \& Griffeth, R.W., Reviewing employee turnover: focusing on proximal withdrawal states and an expanded criterion, Psychological Bulletin, 138(5), 2012, 831-858.

[10] Maslow, A. H.,The Instinctoid Nature of Basic Needs. Journal of Personality, 22(3), 1954, 326.

[11] Näswall, K., Sverke, M., \& Hellgren J., The moderating role of personality characteristics on the relationship between job insecurity and strain, Work \& Stress, 19(1), 2005, 37-49.
[12] Carlson, D.S., Grzywacz, J.G., Ferguson, M., Hunter, E.M., Clinch, C.R., \& Arcury T.A., Health and turnover of working mothers after childbirth via the work-family interface: An analysis across time, Journal of Applied Psychology, 96(5), 2011, 1045-1054.

[13] Van den Broeck, A., De Cuyper, N., De Witte, H., \& Vansteenkiste, M., Not all job demands are equal: Differentiating job hindrances and job challenges in the Job Demands-Resources model, European Journal of Work and Organizational Psychology, 19(6), 2010, 735-759.

[14] Huang, G.H., Niu, X., Lee, C., \& Ashford, S.J., Differentiating cognitive and affective job insecurity: Antecedents and outcomes. Journal of Organizational Behavior, 33(6), 2012, 752-769.

[15] Wang, H.J., Lu, C.Q., \& Lu, L., Do people with traditional values suffer more from job insecurity? The moderating effects of traditionality, European Journal of Work and Organizational Psychology, 23(1), 2014, 107-117.

[16] Allen, N. J., \& Meyer, J. P., The measurement and antecedents of affective, continuance and normative commitment to the organization. Journal of Occupational and Organizational Psychology, 63(1), 1990, 118

[17] Fischer, R., \& Mansel,1 A., Commitment across cultures: A metaanalytical approach. Journal of International Business Studies, 40(8), 2009, 1339-1358.

[18] Ng, T.W., \& Feldman, D.C., Affective organizational commitment and citizenship behavior: Linear and non-linear moderating effects of organizational tenure, Journal of Vocational Behavior, 79(2), 2011, 528537.

[19] Klein, H.J., Molloy, J.C., \& Brinsfield, C.T., Reconceptualizing workplace commitment to redress a stretched construct: Revisiting assumptions and removing confounds, Academy of Management Review, 37(1), 2012, 130-151.

[20] Fei, H.T., Peasantry and gentry: an interpretation of Chinese social structure and its changes, American Journal of Sociology, 521, 1946, 117.

[21] Hwang, K.K., Confucian relationalism and social exchange, in Foundations of Chinese Psychology, New York, Springer, 2012.

[22] Yang, M. H. Gifts, favors and banquets.1994.

[23] Wu, T.J., Tsai, H.T., \& Yeh, S.P. The role of manager's locus of control between perceived guanxi and leadership behavior in family business, Revista Internacional de Sociología, 72(2), 2014, 87-104.

[24] Taormina, R. J., \& Gao, J. H., A research model for guanxi behavior: antecedents, measures, and outcomes of chinese social networking. Social Science Research, 39(6), 2010, 1195-1212.

[25] Caplan, R. D.. Cobb, S., French, J. R. P., Harrison, R. V., \& Pinneau, S. R., Job demands and worker health. Washington, DC: U.S. Department of Health, Education, and Welfare. 1975.

[26] Baron, R. M., \& Kenny, D. A., The moderator-mediator variable distinction in social psychological research: conceptual, strategic, and statistical considerations. Journal of Personality \& Social Psychology, 51(6), 1986, 1173 